\title{
$O$ ateliê do ator-encenador: uma possibilidade pedagógica
}

\author{
Rejane Kasting Arruda \\ Doutoranda em Artes Cênicas/USP \\ Área de Concentração: Pedagogia do Teatro \\ Orientador: Armando Sergio da Silva \\ Bosista FAPESP \\ Atriz e professora
}

Resumo: Partimos do par "anteparo e impressão digital" - apresentado pela Oficina da Essência (SILVA, 2010) - e da noção de que uma estrutura fundamenta a singularidade da prática. O objetivo é abrir a perspectiva para que o ator possa encenar. Isto na medida em que se cria "arranjos de anteparos" e se orienta por funções implicadas na estrutura da prática. Os procedimentos metodológicos são interseção e criação. A intersecção situa as funções em pensamentos diferentes: fala interna (Kusnet) junto a instrução de jogo (Spolin); encadeamento (Barba); a escrita de um verbo próprio (Stanislavski e Knébel) e o treinamento na imobilidade (Grotowski); além de deslocamento e substituição (psicanálise lacaniana). A criação permite, a partir da observação, a extração de novas funções (enquadramento, exposição, incidência), bem como a demonstração de sua implicação na prática.

Palavras-chave: ator, encenação, pedagogia.

Title: The studio of actor-director: a pedagogical possibility

Abstract: We start from the "anteparo" and "fingerprint" concepts - introduced by de Silva's "Oficina da Essência" (SILVA, 2010) - and from the idea that a structure is the foundation of the singularity of theatrical pratics. This article aims to open a new perspective for the actor him or herself be able to create the theatrical scene, by using "anteparos arranges" and by some functions implied in the pratics' strucuture. The metodological procedures are intersection and creation. Intersection puts the functions of theatrical poetics in different systems: inside speech (Kusnet) side by side with game instruction (Spolin); chaining (Barba); the writing of a personal verb (Stanislavski and Knébel) and the training of imobility (Grotowski); dislocation and replacement (Lacan's psychoanalysis). By observation, one extracts new functions (framing, exposing, incidence), and also demonstrates its practical implications.

Keywords: actor, mise-en-scène, pedagogy

Título: El estudio del actor y director: una posibilidad pedagógica

Resumen: A partir de los conceptos de "anteparo" y "huella digital" - presentados en la "Oficina de la Esencia" (SILVA, 2010) - y de la noción de que la estructura fundamenta la singularidad de la práctica. El objetivo es abrir la perspectiva para que el actor ponga en escena. Eso es posible a partir de la creación de conjuntos de "anteparos" y de la orientación por funciones implicadas en la estructura de la práctica teatral. Los procedimientos metodológicos son: intersección y creación. La intersección sitúa las funciones en pensamientos distintos: voz interna (Kusnet) junto a instrucción de juego (Spolin); encadenamiento (Barba); la escritura de un verbo propio (Stanislavski y Knébel) y el 
entrenamiento en la inmovilidad (Grotowski); además de deslizamiento y substitución (psicoanálisis de Lacan). La creación permite, a partir de la observación, la extracción de nuevas funciones (encuadre, exposición, incidencia), y también la demostración de su implicación en la práctica.

Palabras-clave: actor, puesta en escena, pedagogía.

A noção de "anteparo" foi elaborada inicialmente pelo Prof. Dr. Armando Sergio da Silva em sua Oficina da Essência (livre docência na Universidade de São Paulo). ${ }^{1}$ Quando dizemos "anteparo", estamos nos referindo aos materiais que o ator utiliza para realizar o seu jogo de criação cênica. Trata-se de materiais heterônimos, com os quais o ator "triangula": "não existe só eu e o meu corpo; mas eu, o meu corpo e o anteparo" (SILVA, 2010). Anteparo é aquilo com o que o ator detalha e recorta o corpo; é o material que se maneja para que o corpo "responda", "produza"; é o material com o qual o ator "dinamiza o corpo"; é o ponto de partida para o improviso ou para a composição; o elemento que possui anterioridade lógica em relação à ação inscrita, impressa, em cena.

A alusão à função de "proteção" veicula o termo anteparo ao desamparo - de um corpo abandonado à situação de exposição - que traz consigo a pulsão (à vida). É com o anteparo que o corpo pulsional, ${ }^{2}$ em abandono, pode ser construído como cênico, ou seja, talhado - com talhos que, no corpo, se apresentam como "letras" de uma escritura (cênica). O anteparo é, portanto, este elemento que possui certa anterioridade (lógica) em relação ao que em cena brota porque, dele, se extrai uma incidência. A ação que brota é a resultante da atuação não de apenas um, mas de vários anteparos. Estes atuam em arranjo, articulados (em cadeias) a outros que, por sua vez, estão escondidos. Atuando juntos, os anteparos deixam brotar algo que é diferente de todos eles juntos; algo que é heterônimo e que restou daquela atuação conjunta; um resto que se fixa em cena; letras da escritura (cênica); portanto, que permitem tanto a escuta quanto a leitura (interpretação) - isto na medida em que o espectador relaciona o que escuta com outros significantes (preenchendo as entrelinhas, associando, tecendo a sua própria interpretação).

Este é o ponto de partida da pesquisa de doutoramento intitulada "O Ateliê do AtorEncenador": o anteparo como uma instância estrutural do trabalho do ator. É esta a nossa hipótese de partida: utilizando anteparos, maneja-se o corpo e, expondo-os em cena, se “encena". Para trabalhar esta hipótese, lançamos mão de uma prática. Ou seja, a criação nos 
serve como um método de pesquisa. É com a criação que problematizamos os procedimentos; é a partir da criação que construímos conceitos que nos permitem detalhar e descrever melhor o que pode ser transmitido a título de uma pedagogia do ator. ${ }^{3}$ É com a criação que observamos funções que - detectadas também em outros sistemas de trabalho - são formalizadas como estruturais. ${ }^{4}$

Em um dos encontros do Centro de Pesquisa em Experimentação Cênica do Ator (CEPECA), ${ }^{5}$ coordenado por Silva, escuto da boca do "professor Armando" (como o chamamos): "a noção não é original, pois se vê anteparos por toda parte" (SILVA, 2010). O fato da "função do anteparo" estar presente em diferentes formalizações do trabalho do ator (como em Stanislávski, Barba, Grotowski, Brecht, Kusnet, Spolin, etc) é um sinal do seu caráter estrutural. $\mathrm{O}$ anteparo é uma função que se repete nas diferentes poéticas e que suporta diferentes modalidades.

Na Oficina da Essência, Silva propõe uma divisão (a título de pedagogia, pois os anteparos atuam juntos) nas modalidades "palavra", "objeto", "imagem" e o que ele chama de "anteparo de sensação": objetos que poderíamos chamar de "táteis", como a água ou algo com odor forte (como um queijo gorgonzola). Estas sensações são inscritas, impressas, na superfície do corpo - nas suas bordas, podemos dizer (internas e externas) - em termos de ação física, ou, para introduzi-lo, em termos de impressão digital: "digital" porque "cada um reage de um jeito ao anteparo" (SILVA, 2010). Se temos modalidades diferentes de anteparos, podemos observar, em diferentes procedimentos de trabalho, uma ênfase maior em uma ou em outra. É quando vemos a complexidade de um sistema verbal, preso ao texto do autor e construído, em nome próprio, pelo próprio ator - capaz de produzir, para a cena, uma "verdade" (termo usado por Stanislávski e que precisaria ser problematizado).

Stanislávski propõe uma rede de anteparos verbais articulados: verbos-de-ação, monólogo-interior, objetivos, "mágicos se", "tudo o que ouço, toco e vejo em cena" (KNÉBEL, 2005) e ainda um texto próprio que substitui temporariamente a fala da personagem (e que, depois, em caminho inverso, será substituído por ela) - enfim, uma rede complexa de anteparos que atuam sobre o corpo (Cf. STANISLÁVSKI, 2005). Este é apenas um exemplo. $\mathrm{O}$ teatro produz significantes singulares, que atuam (enquanto imagem acústica) sobre o corpo - na medida em que também articulam imagens visuais. Por exemplo, o vetor transmitido por Grotowski e nomeado "impulso de dentro para fora" (Cf. GROTOWSKI, 
1993, p. 18-26): se tomarmos este significante ${ }^{6}$ como um anteparo - ou seja, se a imagem acústica e visual deste termo fizer incidência sobre o corpo - criamos impressões digitais que podem ser, enquanto produção cênica, manejadas.

A hipótese de partida do nosso projeto é: "o anteparo estrutura a nossa experiência" ou "o anteparo estrutura a experiência cênica". Podemos construir, com os anteparos, o corpo cênico, ou melhor, as "letras cênicas"; que implicam também as entrelinhas do que se escuta (do significante) - para que o público participe, produzindo, nas fissuras, a sua interpretação. O objetivo da pesquisa é formalizar, descrever este processo - problematizando seus impasses em uma tese de doutorado que, por princípio, deve implicar certa originalidade. Então, de que originalidade se trata? Propomos desdobramentos para a Oficina da Essência, na medida em que intersecções são articuladas. Por intersecções, queremos dizer pontos de cruzamentos em cadeias a princípio autônomas. Por exemplo, a instância da fala interna formulada por Kusnet (1992) ${ }^{71}$ é algo que valoriza a modalidade "palavra" na medida em que mostra que a redução de um monólogo-interior (de um pensamento) - ou dada por associação súbita - pode sustentar a produção física, corporal, em improvisação.

Kusnet também mostra que podemos trabalhar a composição de um arranjo de falas internas diferentes. Se cruzo isto com a Oficina da Essência, tomo a fala interna como um anteparo. Se cruzo a fala interna com o sistema de Spolin, tomo a instrução ${ }^{8}$ como um anteparo. E se tenho duas falas internas atuando juntas, sustento a divisão de foco tão importante em Spolin. Se tenho a divisão de foco bem como o arranjo de anteparos atuando juntos, preciso resolver a sua incidência conjunta naquele instante da cena, produzindo algo novo. A minha impressão digital surge tanto como síntese quanto como encadeamento. Síntese no sentido da condensação (Cf. GROTOWSKI, 1993, p. 18-26): um anteparo apaga o outro, o substitui na cadeia ascendente do eixo vertical - que implica que eles estão em relação sem estarem explicitados em cena. E encadeamento na medida em que o foco se reveza entre os anteparos que atuam juntos - e as suas substituições, dispostas no tempo, como uma alternância entre ações, implica o detalhamento de uma partitura física. Este é um exemplo de como articulamos a Oficina da Essência com outros procedimentos (de Kusnet e Spolin) para, neste caso, valorizarmos a modalidade verbal - que não precisa estar, necessariamente, exposta em cena. Neste sentido, ela é interna: uma fala interna, como diz Kusnet, pois está “oculta” do público (dos ouvidos e olhos do público). 
Quando enfatizamos este divisão entre duas categorias opostas - externo e interno nos deparamos com a polêmica, com o impasse da teoria atoral, a discussão que Grotowski (Cf. 1993, p. 18-26) propõe sobre o vetor do impulso ("de dentro para fora" ou "de fora para dentro") e que permeou a história de nossa práxis. Em um segundo desdobramento para a Oficina da Essência, propomos “o movimento" como uma quarta modalidade de anteparo" : o movimento, como um elemento que podemos isolar, repetir, rememorar e compor com outras modalidades. A impressão digital será sempre a resultante cênica de um arranjo no qual o movimento está presente. O movimento, como anteparo, também enquadra o ator no tempoespaço - ao contrário da palavra que, como um anteparo "interno", não dá o enquadramento (pois cumpre apenas a "função da incidência do significante no corpo"). Ou seja, "o significante passado a gozo" vinca, na superfície corporal (a substância viva de que se goza), ${ }^{10}$ uma letra que, no entanto, precisa ser enquadrada. ${ }^{11}$

$\mathrm{Na}$ psicanálise lacaniana, "o significante passado a gozo" é a letra. ${ }^{12}$ É assim que tomamos a impressão digital: a resultante da incidência do significante no corpo - passado a gozo. A impressão digital é a letra resultante da incidência de significantes encadeados e articulados na vertical - com outros que estão apagados, condensados. Enfim, esta incidência, ela não enquadra o corpo - não define o momento de início e fim no tempo cronológico ou o seu desenho no espaço. Ou seja, se por um lado se incide enquanto o recorte de um gozo, por outro, não se ordena a sua resolução. Ao contrário, se temos, por exemplo, um som em determinado ponto da escritura cênica, e um outro como o marco do final de uma incidência, temos um enquadre. Sabemos que certa incidência entrará naquele ponto específico e se desenvolverá (livremente, como um improviso) até o outro ponto - onde será, então, cortada, substituída, por outra, ou seja, por outro anteparo "interno" (ou oculto) que fará incidência.

Então, o que propomos, como estrutura do trabalho, é um jogo entre estas duas funções, um jogo entre anteparos externos e internos - os que enquadram o corpo e os que fazem incidência sobre ele. O movimento faz parte da função do enquadre por dizer respeito à organização espaço-temporal. Assim como a ficção que, com as suas imagens (bordadas na imaginação), enquadram um corpo que é inscrito, em cena, de forma brutal, ou seja, como letra. Propomos, então, como um segundo desdobramento para a Oficina da Essência, esta função: o enquadramento - que tanto a ficção quanto a abstração do movimento podem exercer. De maneira que "o impasse dentro-fora" se resolve desta maneira. Os princípios "de 
dentro para fora" e "de fora para dentro" não são dicotômicos, pois trata-se de funções diferentes que atuam juntas: o enquadramento e a função de incidência de significantes no corpo.

São estes desdobramentos que implicam a originalidade de nossa pesquisa. Eles são formulados na medida em que extraímos consequências de intersecções de cadeias autônomas: Kusnet e Spolin para a função da incidência ("interna”) do significante que atua em conjunto e divide o foco; Stanislávski e Grotowski (que divergiam neste ponto) para, com a importância dada contemporaneamente ao movimento e à oposição à ficção, formularmos a noção do enquadramento - na medida em que o movimento não se funda na ação figurativa, mas na abstrata. E ainda, cruzando experimentos com o som de um Bob Wilson ou outros que tomam o som na sua materialidade (sem evocar a ordem ficcional associada mentalmente pelo espectador). Deparamos-nos com cadeias, formulações autônomas na práxis teatral, e as cruzamos. O ponto de cruzamento se expressa como uma função. A extração desta função nos auxilia na prática e na sua formalização enquanto teoria transmissível. Constituímos, assim, com a nossa pesquisa, um espetáculo como o documento que privilegiará uma problematização destas funções.

Esta problematização implica a aproximação com questões contemporâneas. A obra, como escritura, é constituída no bojo de certas contradições - e se configura como um objeto privilegiado para o olhar e o debate. Por exemplo, um dos materiais da Oficina da Essênciados quais o ator lança mão para construir a sua escritura - é o enredo, ou seja, uma história. Contemporaneamente, com a influência da performance, o teatro se divorciou do enredo como algo necessário à sua sobrevivência. Em busca do que "eu sou" o teatro disse: "eu não sou a história". ${ }^{13}$ No entanto, até que ponto o ator pode recuperar esta instância como um dos elementos em jogo, um campo de extração de imagens, palavras e objetos, que servem a uma escritura autônoma? Autônoma porque produtora de um pensamento que ultrapassa o enredo, já que a sua poética não é a poética do enredo ou da história, mas a relação entre estas duas funções que apontamos (incidência do significante no corpo e enquadramento) - e na medida em que se pode propor um jogo de enquadres para este corpo afetado?

Propomos uma segunda hipótese, portanto. O pensamento que a obra traz está implicado na poética teatral como singular - e se vale das duas funções expostas para a sua construção. Um pensamento que "vem da obra": isto significa que o ator, enquanto artista que 
encena (e ele encena na medida em que expõe anteparos e joga com estas duas funções), não tem o domínio do que dali brota enquanto pensamento. $\mathrm{O}$ ator, enquanto artista que encena, delicadamente, coloca-se também em um lugar de observador do que surge. E isto, enquanto se enlaça, articula seus tecidos corporais e pulsionais a uma produção à revelia - em que sua posição se revelou paradoxal: agente e objeto. Terminamos com isto por ora.

\section{Referências}

FREUD, S. A interpretação dos sonhos. Rio de Janeiro: Imago, 2001.

GROTOWSKI, J. Respuesta a Stanislavski. Máscara - Cuaderno Iberamericado de Reflexion sobre Esconologia (Grotowski), México, año 3, n. 11-12. p. 18-26, 1993.

KNÉBEL. M. La poetica de la pedagogia teatral. México: Siglo XXI, 2002.

KUSNET, E. Ator e método. São Paulo: Hucitec, 1992.

LACAN, J. A instância da letra no inconsciente ou a razão desde Freud. In: LACAN, J. Escritos. Rio de Janeiro: Jorge Zahar, 1998.

LEHMANN, H. O teatro pós-dramático. São Paulo: Cosac Naify, 2007.

SILVA, A. S. Interpretação: uma oficina da essência. In: (Org.). CEPECA: Uma oficina de PesquisAtores. São Paulo: Sociedade Amigos da Praça, 2010.

STANISLAVSKI, C. A criação de um papel. Rio de Janeiro: Civilização Brasileira, 2005.

SOLER, C. O “corpo falante”. In: FINGERMANN, D. (Org.) Caderno de Stylus, n.1. Rio de Janeiro: Internacional dos Fóruns do Campo Lacaniano, 2010.

SPOLIN, V. Improvisação para o teatro. São Paulo: Perspectiva, 1999.

\footnotetext{
1 Estaremos utilizando também proposições proferidas oralmente, em encontros presenciais com nosso orientador.

${ }^{2}$ A noção de corpo pulsional é muito bem formulada nas produções do Outrarte - centro de pesquisa na Universidade de Campinas que se dedica a elaborações da interface entre psicanálise lacaniana e arte - dirigido pela Profa. Dra. Nina de Araújo Leite.

${ }^{3}$ Estamos construindo conceitos como "campo de extração". Um romance, uma obra de um pintor ou um filme (por exemplo) funcionam como campo de extração de anteparos: materiais são recortados, isolados e extraídos de dentro de um "campo".
} 
${ }^{4}$ Colocando nossa prática em diálogo com pesquisas documentadas na história da práxis teatral, extraímos funções - que se apresentam como estruturais e são manejadas durante o processo de criação - como a função do anteparo, a função do arranjo, a função do deixar-se levar, a função da divisão do foco, a função da incidência do significante no corpo, a função do texto de bastidor, a função do enquadramento.

${ }^{5}$ O CEPECA é coordenado por Silva, veiculado ao Departamento de Artes Cênicas da ECA-USP e inscrito no CNPq. Às quintas-feiras de manhã, reúnem-se, atualmente, dezessete pesquisadores (entre doutorandos, mestres, mestrandos e alunos de graduação), para apresentar suas produções e debater suas pesquisas em função de suas práticas. As reuniões são abertas à comunidade científica.

${ }^{6}$ Estamos tomando o termo "significante", tal como é formulado na psicanálise lacaniana: algo que diz respeito à estrutura da linguagem (o simbólico); que pode se encadear - oferecendo-se às operações de deslizamento, substituição, condensação, apagamento, rasura - e que, passado a gozo, constitui-se como "letra". O ensino de Lacan foi elaborado e transmitido em 23 seminários, além de seus Escritos, Outros Escritos e conferências com os quais Lacan relia a obra de Freud e propunha diversas articulações com a obra de filósofos como Hegel, Kant, Aristóteles, Heidegger (na medida em que estas o auxiliavam a formalizar e transmitir a experiência psicanalítica). As formulações sobre o significante passaram por variações. Ver mais sobre o "significante passado a gozo" (ou seja, o que foi formalizado como "letra") em SOLER, C. O. (2010). Propomos "tomar um significante como um anteparo" na medida em que tanto o significante quanto o anteparo são elementos que podemos isolar e conjugar com outros.

${ }^{7}$ Se tomarmos a fala interna como uma função, poderemos formular modalidades diferentes, inclusive desvinculando-as do enquadramento oferecido pela ficção (operação que estamos problematizando na pesquisa).

${ }^{8}$ A instrução é uma das principais instâncias formalizadas por Spolin. O seu aforismo, "A instrução atinge o organismo total", indica a operação que estamos formalizando como "incidência do significante no corpo".

${ }^{9}$ Junto à palavra, imagem e objeto.

${ }^{10}$ Assim, chegamos a duas funções fundamentais da poética cênica: o enquadre e a incidência.

11 "O significante atinge o indivíduo corporal, condição para o gozo" (SOLER, 2010).

${ }^{12}$ A "condensação" é, com o deslocamento, uma fundamental operação da linguagem, tal como proposta por Freud em A interpretação dos sonhos e retomada por Lacan.

${ }^{13}$ Ver a problemática do teatro contemporâneo tal como é discutida em LEHMANN, H.T. (2007). 